\title{
Low-cost, environmentally friendly route for producing CFRP laminates with microfibrillated cellulose interphase
}

\author{
B. E. B. Uribe, E. M. S. Chiromito, A. J. F. Carvalho, J. R. Tarpani* \\ Department of Materials Engineering, São Carlos School of Engineering, University of São Paulo 13566-590, Brazil
}

Received 23 June 2016; accepted in revised form 1 September 2016

\begin{abstract}
In this paper, a cost-effective and eco-friendly method to improve mechanical performance in continuous carbon fiber-reinforced polymer (CFRP) matrix composites is presented. Unsized fiber fabric preforms are coated with self-assembling sugarcane bagasse microfibrillated cellulose, and undergo vacuum-assisted liquid epoxy resin infusion to produce solid laminates after curing at ambient temperature. Quasi-static tensile, flexural and short beam testing at room temperature indicated that the stiffness, ultimate strength and toughness at ultimate load of the brand-new two-level hierarchical composite are substantially higher than in baseline, unsized fiber-reinforced epoxy laminate. Atomic force microscopy for height and phase imaging, along with scanning electron microscopy for the fracture surface survey, revealed a $400 \mathrm{~nm}$-thick fiber/matrix interphase wherein microfibrillated cellulose exerts strengthening and toughening roles in the hybrid laminate. Market expansion of this class of continuous fiber-reinforced-polymer matrix composites exhibiting remarkable mechanical performance/cost ratios is thus conceivable.
\end{abstract}

Keywords: polymer composites, hierarchical structure, interphase, nanocellulose

\section{Introduction}

The reinforcement of polymer matrices with continuous carbon fibers $(\mathrm{CF})$, giving rise to so-called carbon fiber-reinforced polymers/plastics (CFRP) composites is a major issue in the space, aerospace, naval, wind and oil and gas energy industries because of their need for construction materials that exhibit very high structural efficiency (i.e., exceptional strength/ density and stiffness/density ratios). The improvement in interfacial strength between the polymer matrix and reinforcing fiber system leading to the enhancement of overall mechanical performance of CFRPs has always been sought by materials scientists, since the region separating the bulk polymer from the fiber reinforcement is of utmost importance to load transference and distribution.

Kim and Mai [1] and Pegoretti et al. [2] discovered that the shear strength of a fibrous polymer composite is closely related to the shear strength of the fibersurrounding polymer matrix domain. They also noted that the latter property strongly depends upon the mechanical performance of the interphase, which constitutes an intermediate, different phase when compared to the reinforcing fiber and the bulk resin [3]. Many efforts were then devoted to build strong fiber/ matrix interphases by controlling physicochemical interactions and frictional forces acting on this particular region of composite systems [4].

That achievement [1,2] allowed efficient hierarchical composite structures to be technologically addressed and developed, aiming not only to improve the mechanical strength but also to mitigate interlaminar, intralaminar and translaminar damage, hence enhancing the fracture toughness as well [57]. For instance, the use of fillers such as monolayer graphene [8-10], Ytterbium fluoride nanoparticles

\footnotetext{
*Corresponding author, e-mail: jrpan@sc.usp.br (C) BME-PT
} 
$[11,12]$, and carbon nanotubes $[6,13-15]$ as hierarchical strengthening and toughening substructures has been recently developed; however, their expensive and laborious methods of synthesis and processing are also known. To overcome this limitation, a simple route was recently found by incorporating cellulose nanocrystals (CNC, $0.17 \%$ in weight) on a glass fiber surface, increasing the ultimate tensile and flexural strength of the composite system by 10 and $40 \%$, respectively [16].

More recently, Uribe et al. [17] employed microfibrillated cellulose (MFC) $[18,19]$, the cheapest cellulose nanoderivative [20], to coat reinforcing glass fibers in epoxy-matrix composite laminates, thus obtaining very promising results with regard to overall mechanical performance improvement. It is worth mentioning that MFC has been incorporated so far to fiber-reinforced polymer matrix composites only by solvent exchange in the liquid polymer bulk [21,22], thus preventing its use in cost-effective vacuum-assisted liquid resin infusion manufacturing techniques where good flow, permeability and wettability properties are of critical importance [23, 24].

This research proposes a facile and affordable route for producing low-cost and environmentally friendly hierarchical CFRP compounded with microfibrillated cellulose MFC. The innovative manufacturing process aims to overcome the main limiting factors of the mechanical performance of unsized continuous fiber-reinforced polymer matrix composites; namely, weak fiber/matrix adhesion and the poor mechanical behavior of fiber surrounding-matrix regions. In this sense, this study contributes in an effective and sustainable way to the market growth of this class of continuous fiber-reinforced-polymer matrix composites, which exhibit optimum performance/cost ratios.

\section{Materials and methods}

\subsection{Raw-materials}

The MFC utilized here was synthesized from cane bagasse, as described elsewhere [19]. Continuous PAN-based unsized CF in the form of $0.30 \mathrm{~mm}$-thick bidirectional plain-weave fabric displaying an areal weight of $200 \mathrm{~g} / \mathrm{m}^{2}$ with 5 bundles $/ \mathrm{cm}$ in both the warp and weft directions, $3 \mathrm{~K}$ filaments per bundle, provided by Fibertex Brazil ${ }^{\mathrm{TM}}$, was employed as the main reinforcing structure in the hierarchical composite laminate. It is worth noting that, according to the manufacturer's price list, the unsized CF fabric grade costs approximately one-tenth of the sized one, which is a very compelling argument for the adoption of the former reinforcement category coated with a cost-efficient green interphase-forming agent, as proposed here. A two-phase liquid system comprising Araldite LY 1316 - 2 BR epoxy resin based on bisphenol A diglycidyl ether (DGEBA) monomer and Aradur HY 2954 hardener was purchased from Huntsman Brazil ${ }^{\mathrm{TM}}$.

Good transparency, solvent and filler-free nature, the possibility of cure at ambient temperature, excellent balance of mechanical, thermal and chemical properties, optimal dimensional stability are characteristics of this thermosetting resin system.

\subsection{Manufacturing MFC-treated and neat CFRP laminates}

Unsized (neat) CF fabric preforms were dipped in aqueous MFC suspension ( $0.1 \%$ MFC in weight) for impregnation, and subsequently dried in oven for $3 \mathrm{~h}$ at $102{ }^{\circ} \mathrm{C}$ until weight loss was negligible.

Five MFC-impregnated plies with in plane dimensions of $300 \times 200 \mathrm{~mm}^{2}$ were piled up according to the quasi-isotropic sequence $[(0 / 90),( \pm 45),(0 / 90)$, $( \pm 45),(0 / 90)]$. Liquid epoxy resin system was prepared by stirring it in a propeller mixer, followed by degassing at $-93 \mathrm{kPa}$ for 8 minutes at an ambient temperature of $25^{\circ} \mathrm{C}$. Vacuum-assisted liquid resin infusion on flexible tooling (RIFT [24]) was carried out using the same set of pressures and temperatures given above. One infusion port was positioned at the centre of the shorter rectangle side, and one exit port was located exactly at the opposite edge.

The same procedure was applied to manufacturing a neat $\mathrm{CF}$ composite laminate that served as baseline for mechanical testing.

Typically $3 \mathrm{~h}$ were spent on infusing each composite plaque, giving rise in both cases to $1.5 \mathrm{~mm}$-thick laminates. This slow infusion rate resulted from the relatively high viscosity of the epoxy resin system utilized, ranging from 350 to $400 \mathrm{cps}$, which is more indicated to positive pressure resin transfer molding rather than to negative pressure vacuum-assisted infusion (typically 200-300 cps), as performed here. Curing was carried out for $12 \mathrm{~h}$ at room temperature, with the first $4 \mathrm{~h}$ under a vacuum bagging pressure of $-50 \mathrm{kPa}$ and the remaining time at atmospheric pressure. Figure 1 summarizes the basic steps of the proposed methodology to obtain MFC-based hierarchical CFRP laminates. 


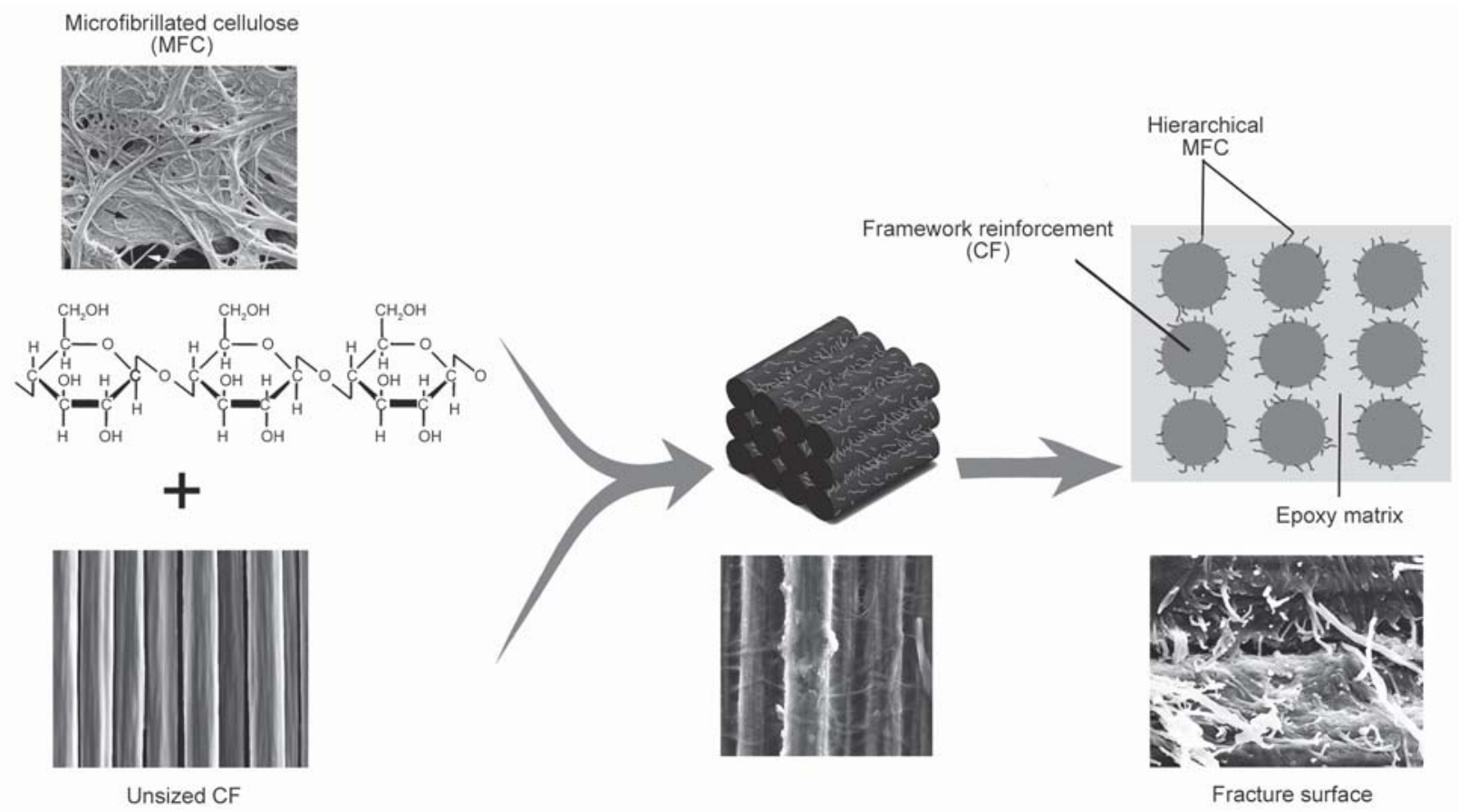

Figure 1. Schematic diagram of the innovative production route of MFC-based hierarchical CFRP laminate

\subsection{Test coupon preparation}

Test coupons were machined from CFRP laminates by employing a rotating thin water-cooled diamond circular saw cutting blade. Finishing of test coupons' edges was performed with dry 600 grit sandpaper. Specifically for tensile testing, CFRP tabs were bonded to both sides at the ends of the specimens in order to prevent their premature failure by grip-inducing damage. Test coupons length (i.e. the largest dimension) was designed to match the $0^{\circ}$ fiber direction.

\subsection{Mechanical testing}

A microprocessor-based electromechanical universal testing machine EMIC model $23-100^{\mathrm{TM}}$ equipped with $10 \mathrm{kN}$ load cell and axial extensometer with original gage length of $25 \mathrm{~mm}$ was utilized in the mechanical tests performed at ambient temperature of $25^{\circ} \mathrm{C}$.

In quasi-static monotonic tensile testing, five fullthickness test coupons with in plane dimensions of $250 \times 22 \mathrm{~mm}^{2}$ were used for each class of CFRP composite laminates, i.e. conventionally conceived and hierarchically structured. Tests were carried out according to ASTM D3039-08 standard under the displacement-controlled condition, with the test speed fixed at a rate of $2 \mathrm{~mm} / \mathrm{min}$.

In three-point flexural testing, five full-thickness test coupons with in plane dimensions of $90 \times 14 \mathrm{~mm}^{2}$ were utilized for each of the two composite laminate categories. Tests were conducted in accordance with ASTM D7264-08 standard by employing a span length of $60 \mathrm{~mm}$ and a deflection rate of $1 \mathrm{~mm} / \mathrm{min}$ measured at the midspan loading line. A thin film of PEEK (poly-ether-ether-ketone) thermoplastic polymer was placed in between the composite test coupon and, respectively, the acting and the supporting steelmade rollers to avoid untimely failure of the laminates by crush-inducing damage.

In short beam strength (SBS) testing, five full-thickness specimens with in plane dimensions of $18 \times 12 \mathrm{~mm}^{2}$ were tested for each type of composite laminate Tests were executed conforming to ASTM D2344-00 standard by employing a span length of $12 \mathrm{~mm}$ and applying a central load train speed rate of $1 \mathrm{~mm} / \mathrm{min}$. A thin film of PEEK polymer was placed in between the composite test coupon and, respectively, the acting and the supporting steel-made rollers, to avert complications discussed earlier for the flexural test.

\subsection{Dynamic-mechanical analysis (DMA)}

DMA analysis was carried out in Perkin Elmer model DMA $800^{\mathrm{TM}}$ equipment operating under threepoint bend mode (span length of $40 \mathrm{~mm}$ ) with a sinusoidal waveform loading applied at a frequency of $1 \mathrm{~Hz}$. A heating rate of $5^{\circ} \mathrm{C} / \mathrm{min}$ was imposed inside the chamber containing a full-thickness test piece with in plane dimensions of $56 \times 10 \mathrm{~mm}^{2}$. The tem- 
perature range of $-50-300{ }^{\circ} \mathrm{C}$ was fully evaluated to determine the glass transition temperature $\left(T_{\mathrm{g}}\right)$ and the storage modulus $\left(E^{\prime}\right)$ of conventionally designed and hierarchically structured CFRP laminates. Three fullthickness specimens were tested for each of the aforementioned composites, where directives of ASTM D7028-07 standard were followed.

\subsection{Atomic force microscopy (AFM)}

Height and phase imaging were simultaneously carried out in tapping mode in Brucker AFM MultiMode $8 \mathrm{SPM}^{\mathrm{TM}}$ equipment with a scan rate of $1 \mathrm{~Hz}$, using new and slim antimony doped silicon probes with tip radius of $1.5 \mathrm{~nm}$ in forward and backward horizontal movements, drive frequency of $100 \mathrm{kHz}$ and spring constant of $5.0 \mathrm{~N} / \mathrm{m}$. In tapping mode $\mathrm{AFM}$, the cantilever is excited into resonance oscillation with a piezoelectric driver. A NX-10 Park Systems $\mathrm{AFM}^{\mathrm{TM}}$ using tapping mode equipped with a NCHR Nanoworld ${ }^{\mathrm{TM}}$ probe was also used, with a resonance frequency of $320 \mathrm{kHz}$ and a spring constant of $42 \mathrm{~N} / \mathrm{m}$. One single composite sample containing all three materials (i.e., CF, MFC and epoxy resin) was prepared by carefully cutting the observation plane with a water-refrigerated circular saw diamond blade, grinding it with 400 to 2000 grit sandpaper and finally polishing it with water-based $0.05 \mu \mathrm{m}$ alumina suspension. Samples containing respectively a single unsized $\mathrm{CF}$, neat MFC, and a couple of parallel CF coated with MFC were mounted. each material deposited in a separated wafer, and also analyzed by AFM. The images were analyzed with Gwyddion ${ }^{\mathrm{TM}}$ open platform.

\subsection{Fractographic and morphological inspection by scanning electron microscopy (SEM)}

In inspecting the fractographic and morphological features of the hierarchical (MFC-treated CF) epoxy resin matrix composite, a low vacuum, high-resolution FEI Inspect F50 Field Emission SEM ${ }^{\mathrm{TM}}$ was used. The examined surfaces were previously sputter-coated with electrically conductive ultra-thin layers of carbon to improve imaging quality. Secondary electron imaging mode was employed at low accelerating voltages ranging from $2-10 \mathrm{kV}$.

\section{Results and discussion \\ 3.1. Compounding unsized $\mathrm{CF}$ fabrics with MFC substructure}

Figure 2a shows an unfolded MFC structure displaying a typical web-like aspect exhibiting a broad spectrum of fibril diameters and huge specific surface contact area. The black arrows point out, respectively, a $25 \mathrm{~nm}$ diameter nanofiber (left side) and one fibril having a much larger diameter of $175 \mathrm{~nm}$ (right side), as measured via image analysis by Image-JTM open platform.

Figure $2 \mathrm{~b}$ presents the result of compounding $\mathrm{CF}$ with MFC, where a fairly even distribution of nanocellulose fibers over the main CF framework can be noticed. According to Shi and Wang [25], interaction between MFC and CF occurs by physical entanglement (anchor effect) and electrostatic attraction via Van der Waals dipole-dipole forces, with the former predominating over the latter. Precipitates in the form of particles and scales stuck to the CF surface are also seen (as pointed out by black arrows), indicating that a more stringent temperature and stirring control of the MFC bath is necessary to avoid or minimize solid precipitation. In spite of that, nanoscale coalescence effects in the MFC were successfully avoided, giving rise to high-quality (i.e., high-strength) nanocellulose fibrils [26]. In Figure 2b, the white arrows call attention to the MFC filaments varying in diameter from 30 to $180 \mathrm{~nm}$.

Figure $2 \mathrm{c}$ allows the identification of a large amount of MFC free ends (pointed out by the white arrows) derived from the nanometric network substructure, which are readily available to be permeated by the vacuum-infused liquid resin. These numerous free ends constitute physical anchoring sites for the epoxy resin matrix; they also provide very extensive area to chemical interaction between these organic compounds via hydrogen bonding, insofar as cellulose and epoxy typically exhibits hydrophilic nature. Both these effects contribute to increasing the mechanical performance of the hierarchical composite laminate. Several weight measurements of dry, unsized CF fabric samples before and after impregnation with MCF showed that the weight percentage of nanocellulose effectively attached to the CF perform was $0.062 \%$ (in relation to CF mass), with a standard deviation of $0.07 \%$. This confirms the good potential for 

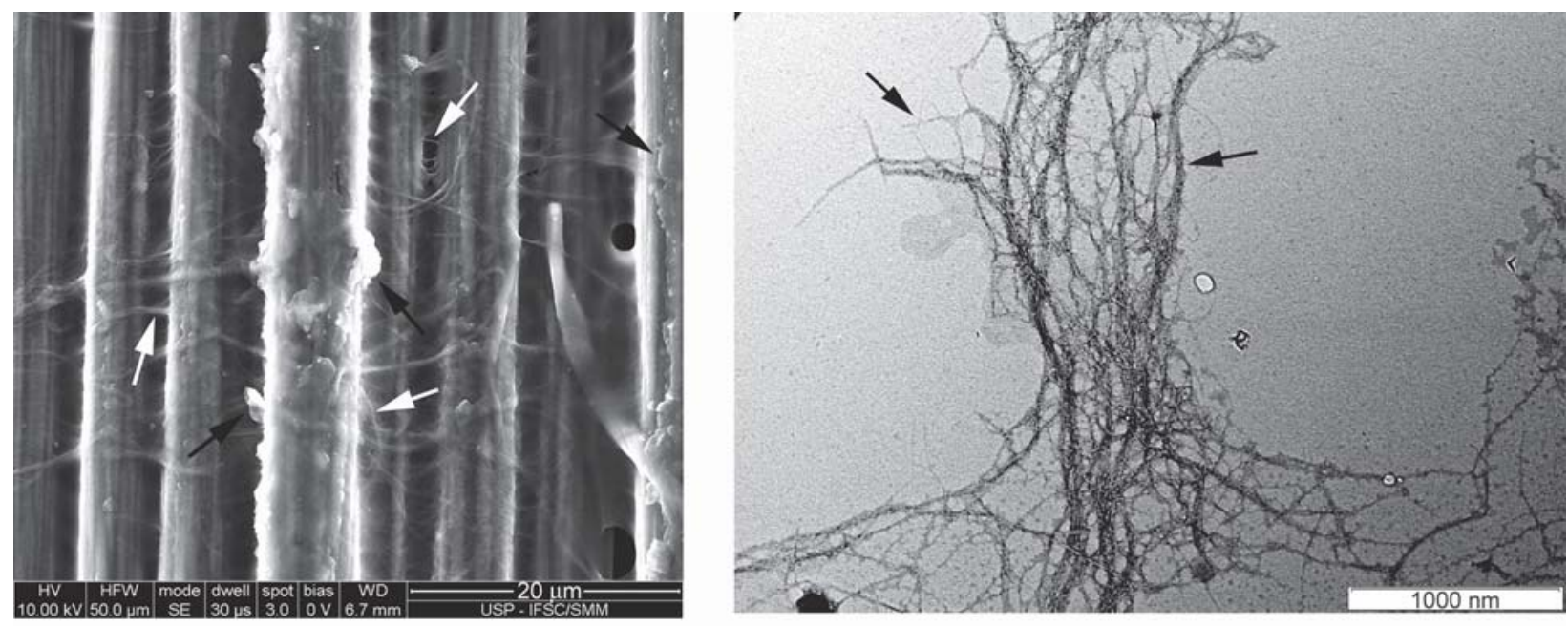

b)

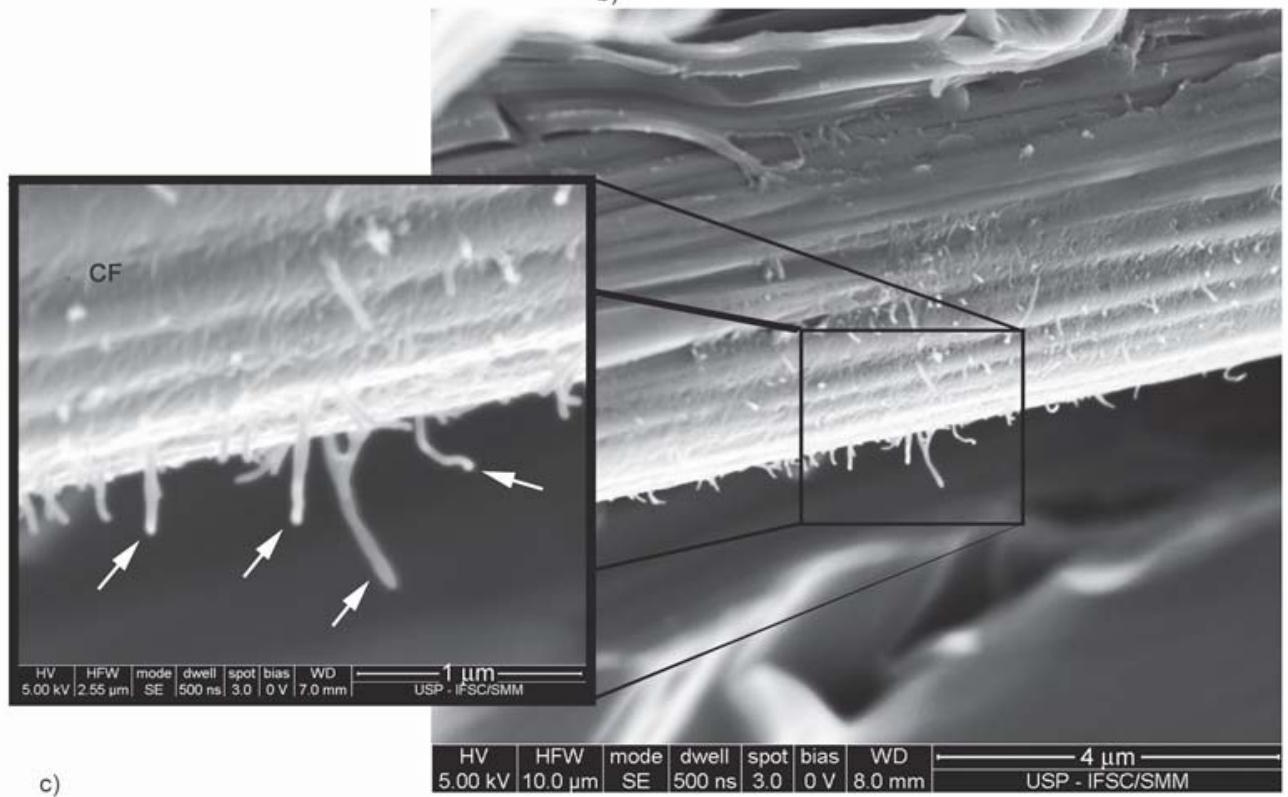

Figure 2. (a) TEM image of weblike MFC structure (Courtesy of [19]); (b) SEM image of unsized CF surface after MFC substructure incorporation; (c) MFC substructure adhered to reinforcing CF displaying numerous free ends

homogeneous dispersion of MFC onto the CF surface, as earlier inferred via SEM analysis (Figure 2b). Finally, it is worth noting that by using a more appropriate (lower viscosity) epoxy resin system and curing the composite laminate at mild temperatures $\left(60^{\circ} \mathrm{C}\right)$ the currently long manufacturing cycle time ( $\approx 18 \mathrm{~h}$ ) can be dramatically reduced, so becoming quite appealing to industry.

\subsection{Mechanical testing}

Figure 3a displays tensile stress-strain curves for, respectively, unsized CF and unsized CF + MFC reinforced epoxy laminates. Recalling that five specimens were tested for each composite type, averaged stress values were plotted along with corresponding standard deviation bars. Both curves were then linearly fitted on a point-to-point basis at selected strain values. The bar graph in Figure $3 \mathrm{~b}$ shows the substantial and similar increase in the composite stiffness $(+27.5 \%)$ and ultimate tensile strength $(+26.2 \%)$ as a result of covering the $\mathrm{CF}$ reinforcement with nanocellulose. This unveils the role of the MFC interphase not only in stiffening the hierarchical composite by transmitting mechanical load more efficiently from the polymer matrix to the main strengthening framework, but also in redistributing the stress more fairly along the whole CF skeleton, hence delaying the laminate fracture process.

These improvements are achievable only as a consequence of effective chemical and/or physical interaction of the MFC agent with both the main CF network and the enveloping thermosetting polymer matrix. It is worth mentioning that the tenacity at ultimate load, as determined by numerically integrat- 

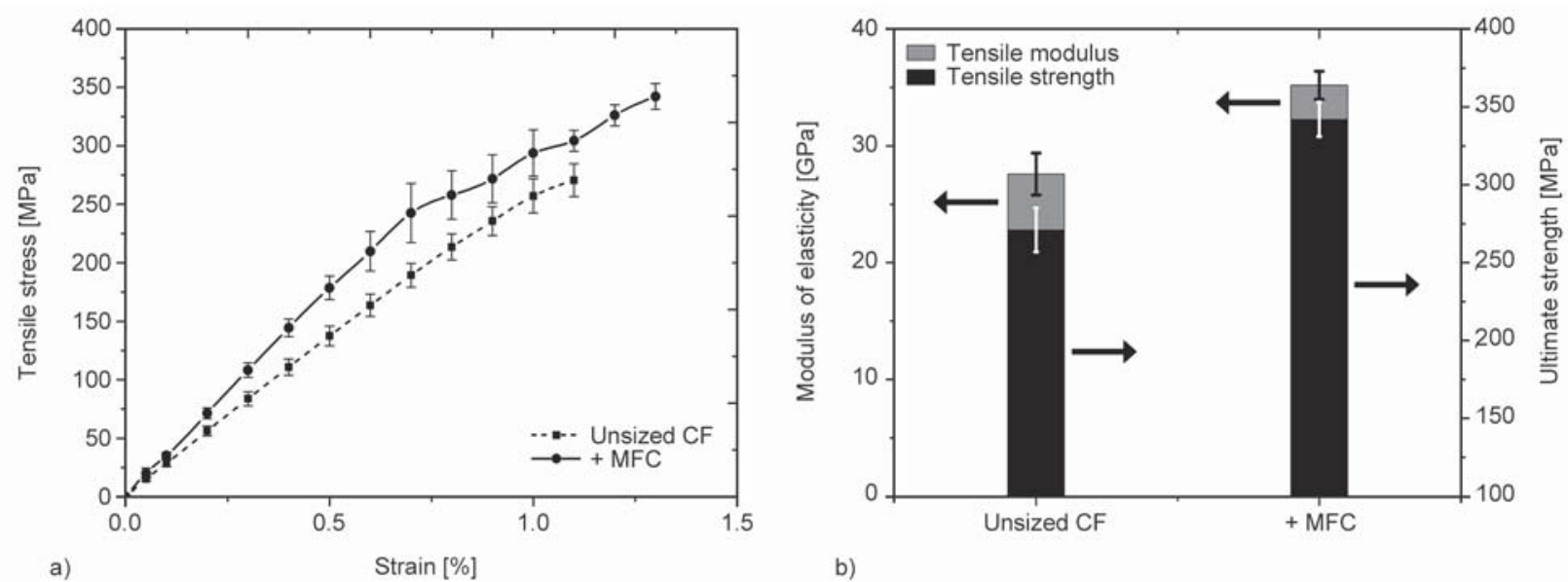

Figure 3. (a) Tensile stress-strain curves of CFRP composite laminates before and after strengthening with MFC; (b) tensile modulus and ultimate strength in both testing conditions

ing the area under the averaged tensile stress-strain curves until that point (e.g., using commercial Origin Software ${ }^{\mathrm{TM}}$ : OriginLab, Northampton, MA), exhibited an outstanding increment of $63.4 \%$ for CF + MFC reinforced epoxy matrix laminate, compared with the sole-unsized CF reinforced one. This clearly indicates that, besides the development of strengthening mechanisms in both the micro- and nanometric levels due to the MFC addition in CFRP laminate, MFC also causes the emergence of micro- and nanotoughening mechanisms. This point will be addressed again in Section 3.5 on the morphological and fractographic features of hierarchically structured CFRP laminate.

It is worth mentioning that in all the presented curves derived from mechanical tests, the last data point plotted corresponds to the ultimate (maximum) load attained during testing, with the remaining data points (the so-called residual strength, if existent) discarded for simplification to the reader.

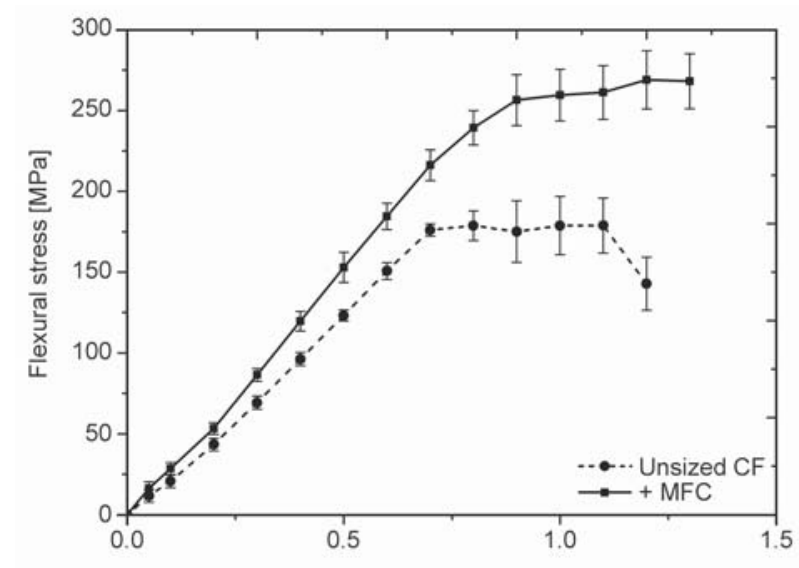

a)

Strain [\%]
Figure 4a displays flexural stress-strain curves for, respectively, unsized CF and unsized CF + MFC reinforced epoxy matrix laminates. Averaged-stress values were once again plotted together with corresponding standard deviation bars. In the same way as for tensile test results, both curves were linearly fitted on a point-to-point basis at selected strain values.

As seen in Figure $4 b$, the improvement in stiffness $(+20.1 \%)$ is somewhat lower than observed under tensile load, whereas the enhancement in the ultimate flexural strength $(+49.2 \%)$ almost doubled when compared to that obtained for the pure tensile mode loading.

One possible explanation for the much higher efficiency of compounding $\mathrm{CF}+\mathrm{MFC}$ in incrementing the ultimate flexural strength than the ultimate tensile case may be due to the fact that failure mechanisms of bent, continuous fiber-reinforced polymer matrix composite materials rely to a large extent on compressive stresses. Under this condition, one fundamental

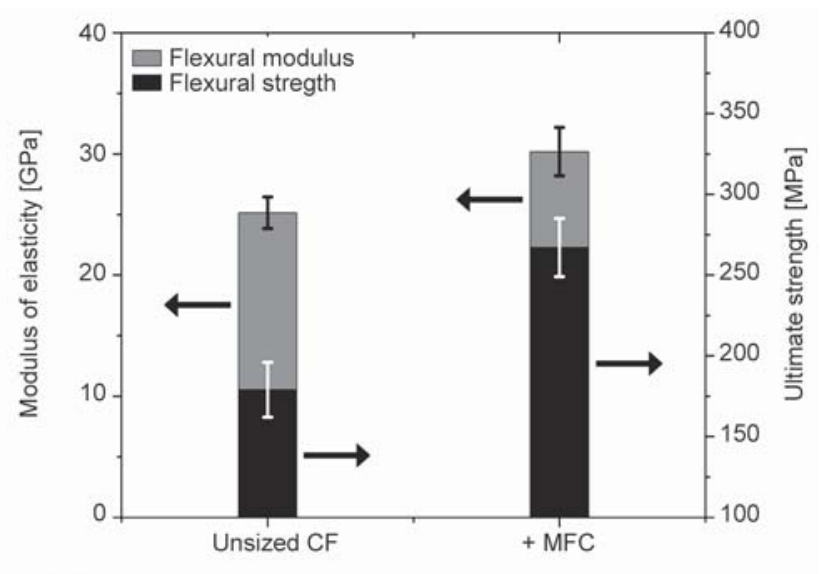

b)

Figure 4. (a) Flexural stress-strain curves of CFRP composite laminates before and after strengthening with MFC; (b) Flexural modulus and ultimate strength in both testing conditions 
function exerted by the matrix is to support the reinforcing fibers against microbuckling failure in the compressively loaded volume of the specimen [27]. In this way, the hierarchical MFC substructure appears to play a major role not only when the composite laminate is stressed in the tensile, but also and perhaps more extensively, in the compressive mode. The tenacity at ultimate load, as calculated from Figure $4 \mathrm{a}$, is $74.4 \%$ greater for the $\mathrm{CF}+\mathrm{MFC}$ reinforced composite than for the laminate exclusively strengthened with unsized CF. Again, there is strong evidence that the direct incorporation of MFC in CF before vacuum-assisted infusion of liquid epoxy resin process, leads to the simultaneous development of strengthening and toughening mechanisms when the final composite laminate is subjected to damage-driven mechanical loads in both tensile and compressive modes.

The resulting averaged shear stress curves (i.e., shear stress values versus displacement at the midspan loading line) of epoxy matrix laminates, reinforced, respectively, with unsized $\mathrm{CF}$ and with unsized $\mathrm{CF}$ covered by MFC, are presented in Figure 5a. The latter composite condition exhibited an average ultimate SBS value $77.3 \%$ higher than that of the former laminate, in full agreement with the behavior verified under both tensile (Figure 3) and flexural (Figure 4) modes of loading. Rosselli and Santare's study [28] of the mechanics of shear stress testing suggests that the laminate thickness-oriented cellulose nanofibers must be the main factor responsible for bearing the applied transverse load. Given that Figure $2 \mathrm{c}$ refers to unsized $\mathrm{CF}$ covered with MFC, the massive presence of MFC free ends with lengths ranging from 0.4 to $0.8 \mu \mathrm{m}$ and positioned exactly orthogonal to the
CF indicates a favorable fibrils orientation leading to greater resistance to failure by delamination [29] in the hierarchically structured composite material. Figure 5a also shows two other important features when comparing the interlaminar mechanical performance of the competing CFRP laminates: the first is the composites' stiffness, which is related to the slope of the shear stress versus displacement curves, while the second is the tenacity at ultimate load, which is given by numerical integration of the area under those curves. Following the same trend as that which was verified earlier for the stiffness and tenacity under both tensile and flexural modes of loading, the hierarchically structured composite exhibited a performance under shear loading as well that was higher than the conventionally designed laminate, respectively, $85.6 \%$ and $65.5 \%$

Figure $5 \mathrm{~b}$ displays micrographs and microfractography of a tested MFC-treated CFRP test coupon showing a typical fracture pattern that the ASTM D234400 standard classifies as a true interlaminar shear failure, therefore validating the procedure and test results for both the composite materials tested in this study.

\subsection{Dynamic-mechanical testing (DMA)}

Figure 6a presents $E^{\prime}$ values of the CFRP laminates in the glassy state (i.e. $T \leq 0^{\circ} \mathrm{C}$ for the conventional CFRP and $T \leq 25^{\circ} \mathrm{C}$ for the MFC-treated one), which are quite comparable. In contrast, in the rubbery polymer zone $\left(T \geq 40^{\circ} \mathrm{C}\right.$ for the conventional CFRP and $T \geq 70^{\circ} \mathrm{C}$ for the MFC-treated one), when the storage modulus is assumed to be strongly related to the crosslink density of neat thermosetting polymers [30], $E^{\prime}$ of the MFC-treated composite is five times

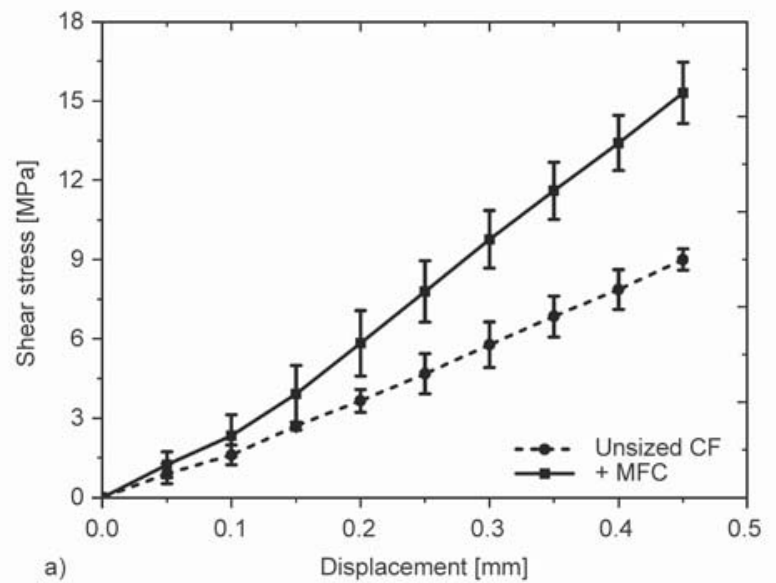

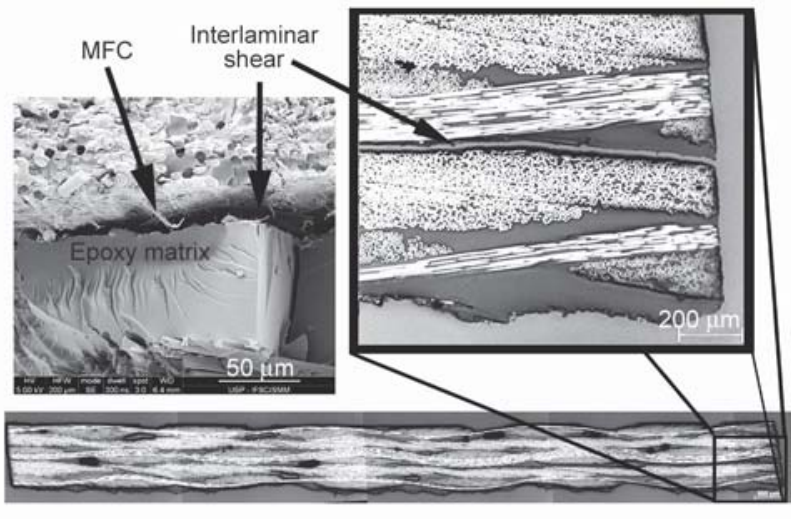

b)

Figure 5. (a) Shear stress behavior of CFRP laminates respectively without and with the presence of MFC substructure; (b) interlaminar shear failure micrographs and microfractography of MFC-treated CFRP laminate 

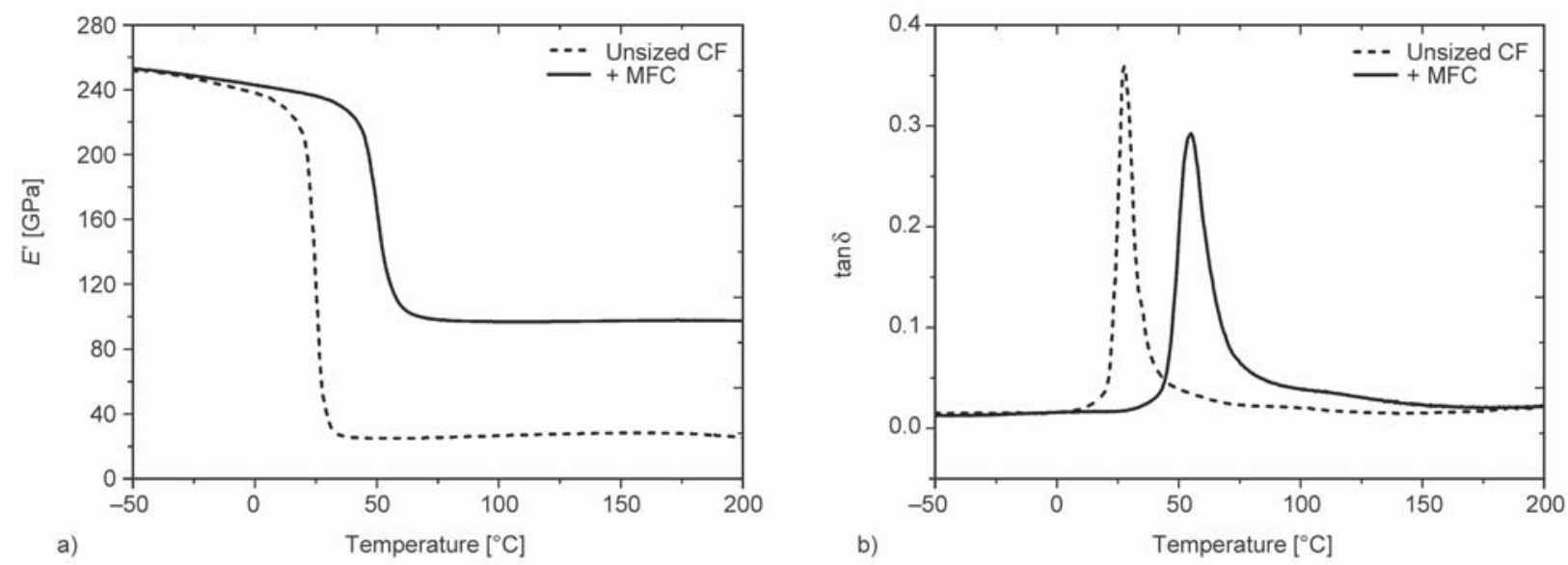

Figure 6. DMA curves displaying (a) $E^{\prime}$, and (b) $\tan \delta$ values of CFRP laminates fabricated respectively without and with the presence of the MFC substructure as an interphase-producing agent.

higher than the untreated one. In this regard, the MFC treatment of the CF framework seems to effectively contribute to restraining the polymer chains' mobility near the fiber/matrix interface. This behavior is in full accordance with stiffness results obtained under quasistatic loading, as reported in the previous section. Figure $6 \mathrm{~b}$ shows $\tan \delta$ versus temperature curves for representative test coupons of the composite laminate classes tested under dynamic-mechanical conditions. The $T_{\mathrm{g}}$ temperature, typically defined at $\tan \delta$ peak [30, 31], was determined as $25^{\circ} \mathrm{C}$ for the baseline (said conventional) CFRP composite, which is well below the $58^{\circ} \mathrm{C}$ found for the hierarchically structured laminate. The substantially higher $T_{\mathrm{g}}$ value exhibited by the latter composite material, as seen in Figure 6a, is derived from the low flexibility of epoxy chain segments next to the MFC-rich interphase region, thus stiffening the local resin matrix. It is worth pointing out that the $\tan \delta$ curves in Figure $6 \mathrm{~b}$ provide not only the $T_{\mathrm{g}}$ values of both the evaluated composite laminates, but also express their damping ability, which can be inferred from the magnitude of the $\tan \delta$ peak [32]. Several studies have shown that the magnitude of $\tan \delta$ in continuous fiber-reinforced polymer matrix composites is inversely proportional to the fiber/matrix mergence $[33,34]$. It can, therefore, be concluded from $T_{\mathrm{g}}$ values and peak heights of the $\tan \delta$ curves depicted in Figure $6 \mathrm{~b}$ that a stronger bond between the $\mathrm{CF}$ and epoxy matrix phases was achieved by incorporating the MFC hierarchical substructure directly onto the originally unsized-CF framework before the RIFT process.

\subsection{Atomic force microscopy (AFM)}

Figure 7a shows the very rough surface topography of the unsized CF surface exhibiting numerous longitudinal grooves. Figure $7 \mathrm{~b}$ displays MFC laid down on a flat substrate, revealing the very heterogeneous nature of constituent fibrils with distinct diameters and lengths, where the longer and thinner ones are more active in terms of mechanical load transference and distribution between the main composite phases.

By comparing the scales related to the height profiles of both CF grooves and MFC substructure in Figures $7 \mathrm{a}$ and $7 \mathrm{~b}$, respectively, one can infer that many MFC diameters are necessary to fulfill the original free gaps on the CF surface, thus giving rise to an effective anchoring (friction-based) mechanism between the micro and nano-reinforcing frameworks. This finding substantiates previous statements by Shi and Wang [25], who also called attention to the marginal effect exerted by weak Van der Waals interaction between MFC and CF in contributing to the strengthening and toughening mechanisms of the composite system.

It is conceivable that the improvement of the mechanical properties of CFRP might be attributed to some extent to the effect of both a large interfacial area and high hydrophilicity of the MFC-modified $\mathrm{CF}$. The latter assumption is supported by Lu et al. [35] who demonstrated the affinity of MFC and epoxy resin. Interestingly, they also proved that changing the MFC nature from hydrophilic to hydrophobic can still enhance MFC-epoxy interaction. This finding can possibly provide an attractive route to further augment the mechanical properties of the composite system studied here. 

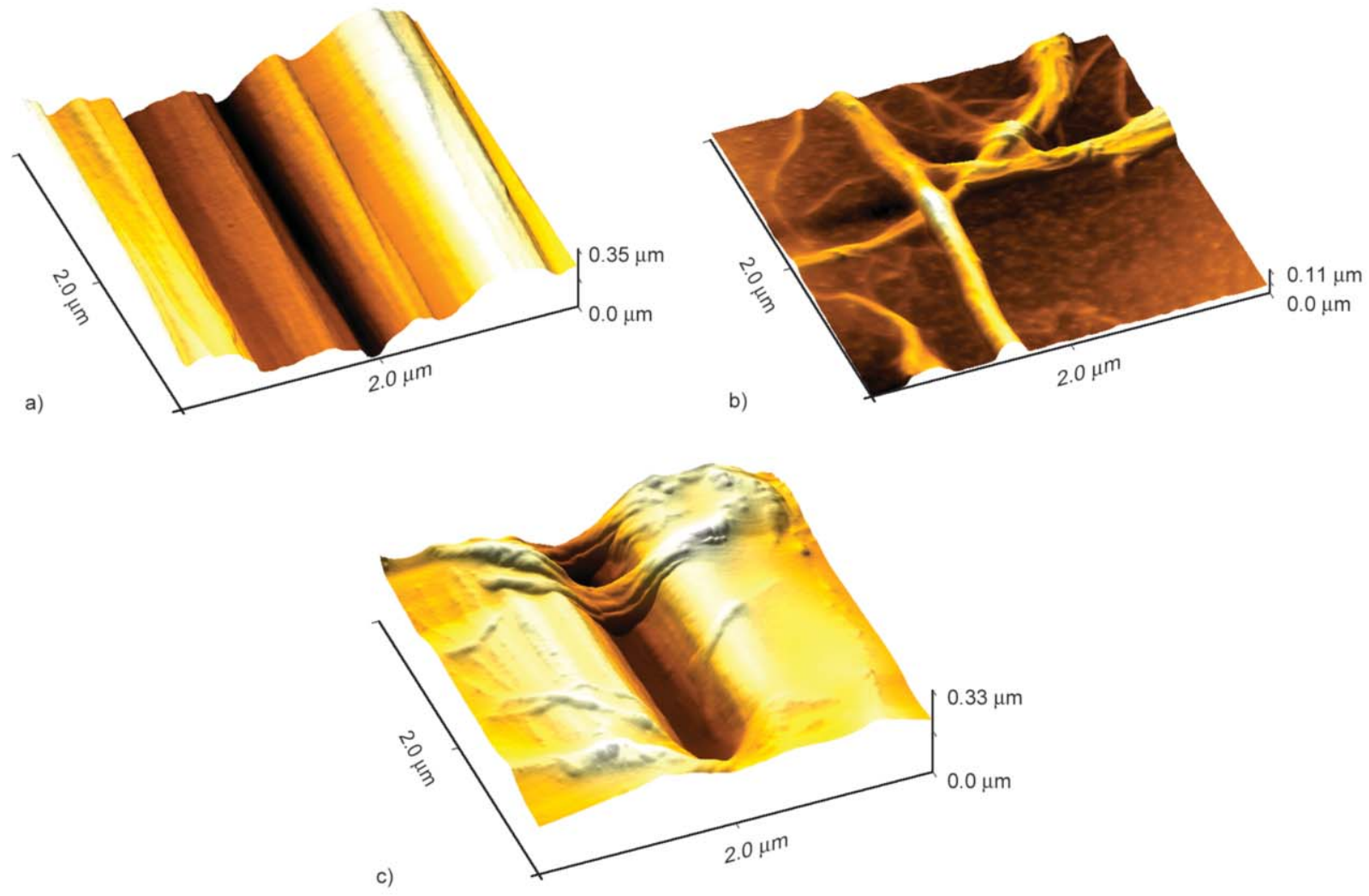

Figure 7. AFM micrographs of: (a) unsized CF surface; (b) neat MFC nanostructure; (c) MFC-treated CF

Figure 7c portrays the efficient merging of MFC to the $\mathrm{CF}$ surface, when the hierarchical reinforcing constituent fully executes its bridging role towards load transference and distribution to the main reinforcing phase.

Figure 8a shows a 2D AFM height image of the hierarchical composite, where the MFC-rich CF inter-

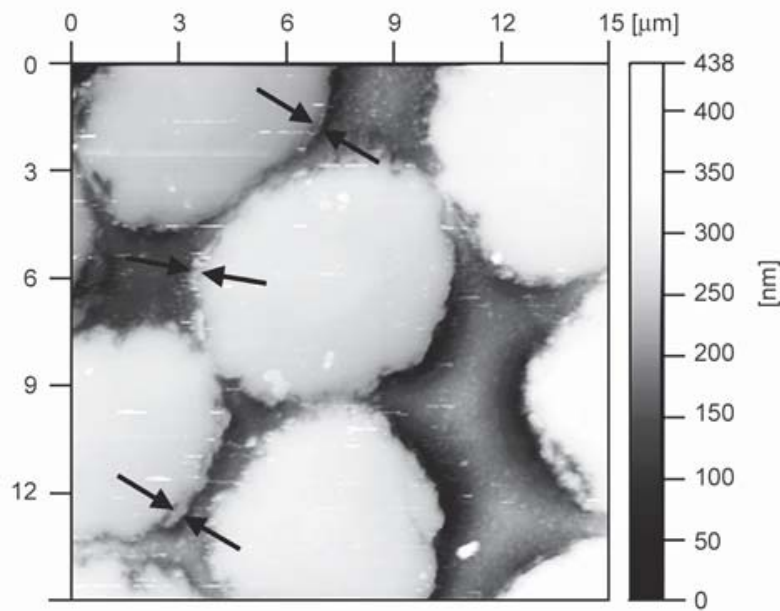

a) phase is clearly observed, as indicated by pairs of black arrows in three distinct locations. Accurate measurements with Image-JTM resulted in an estimated average MFC-rich interphase thickness of $400 \pm 35 \mathrm{~nm}$. Figure $2 \mathrm{c}$ illustrates unsized CF covered with MFC, where MFC free ends with lengths ranging from 0.4 to $0.8 \mu \mathrm{m}$ and positioned exactly orthog-

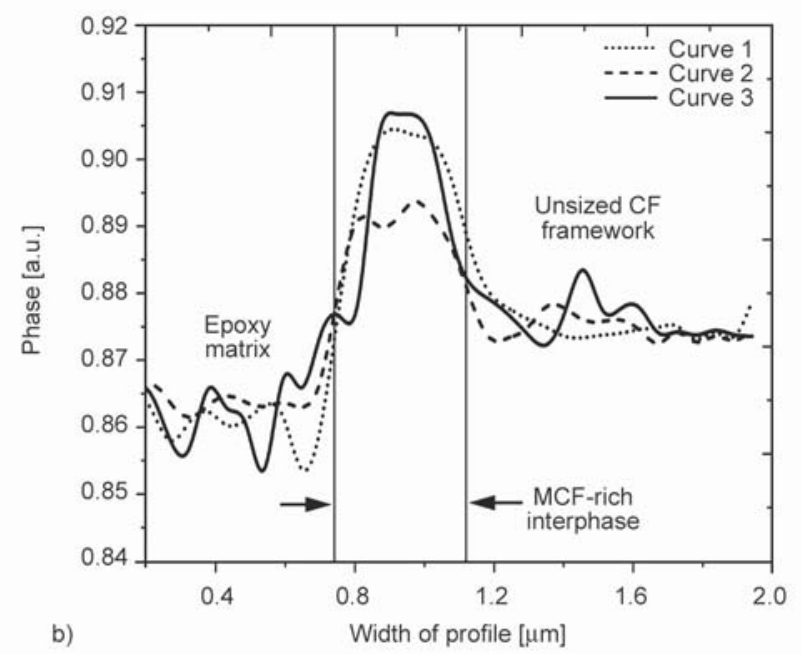

Figure 8. (a) $2 \mathrm{D}$ cross-sectional AFM height image of the hierarchical CF+MFC reinforced epoxy matrix composite laminate; (b) phase linescan profiles crossing respectively the epoxy resin matrix, MFC-rich interphase and reinforcing $\mathrm{CF}$ of the hierarchical composite 
onal to the CF are apparent; therefore, $400 \mathrm{~nm}$ appears to be a very coherent estimation of this interphase thickness.

Figure $8 \mathrm{~b}$ presents lateral force versus displacement curves related to the phase image of the hierarchical composite, which were obtained along three different straight scanlines indicated by pair of arrows in Figure $8 \mathrm{a}$, starting at the epoxy polymer matrix, crossing the MFC-rich interphase region and ending over the $\mathrm{CF}$ surface. The reactive lateral forces originating along the sweeps of the sample surface showed the greatest response over the MFC-rich interphase region, rendering its thickness evaluation of the order of $400 \mathrm{~nm}$. Because of the curvature of the cantilever tip, this value may be somewhat overestimated due to the relatively poor horizontal resolution of AFM technique. Nonetheless, it can be argued that the obtained value is quite similar to that optically estimated from Figure 8a. This provides the doubly calculated parameter at least with necessary robustness to contrast it to the values supplied in the literature for comparable continuous carbon fiber-reinforced epoxy matrix systems.

In this regard, Li et al. [36] found interphase thicknesses ranging from 20 to $80 \mathrm{~nm}$ though a nanoindentation process based on numerical simulation. Munz et al. [37] reported a range from 20 to $80 \mathrm{~nm}$ by measuring the stiffness using AFM force modulation mode, and $\mathrm{Gu}$ et al. [38] determined a value of $118 \mathrm{~nm}$ by employing a nanoscale dynamic me-

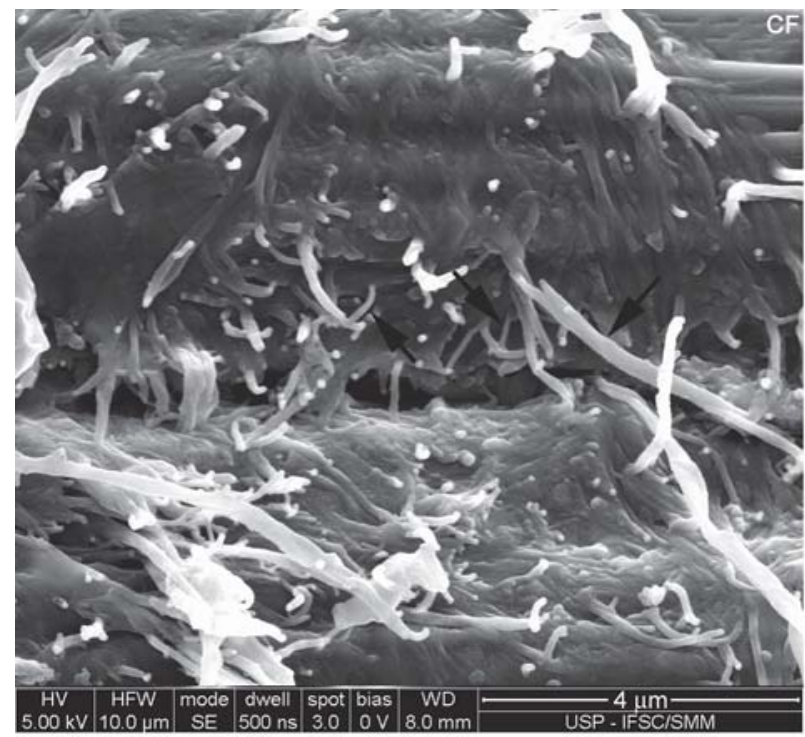

a) chanical imaging technique. Li et al. [39] discovered thicknesses from 80 to $270 \mathrm{~nm}$ by utilizing the modulus mapping technique, which combines dynamic action with the scanning probe microscopy (SPM) function in nanomechanical equipment. Wu et al. [40] described a $200 \mathrm{~nm}$ value using transmission electron microscopy and sample preparations by a focused ion beam, ion beam etching, and ultramicrotomy. Williams et al. [41] estimated a $250 \mathrm{~nm}$ interphase thickness by loading in tension a single fiber embedded in a small supported disk of epoxy matrix, and examining the surface displacements in the resin next to the fiber surface, then contrasting them to what was observed in the bulk matrix.

As one can see, the results obtained here regarding the interphase thickness differ from order of magnitude to minimally double the values reported in the literature.

\subsection{Fractographic and morphological inspection by scanning electron microscopy (SEM)}

Figure 9a shows the peculiar fracture topography developed adjacent to the CF surface during tensile testing. Massive blocks of solid epoxy resin completely permeating MFC cells resemble earthworms in soil, suggesting noteworthy dispersion and strong interaction (i.e., remarkable compatibility) between the matrix and reinforcing nanofibrils. This gives the composite effective nanotoughening mechanisms like

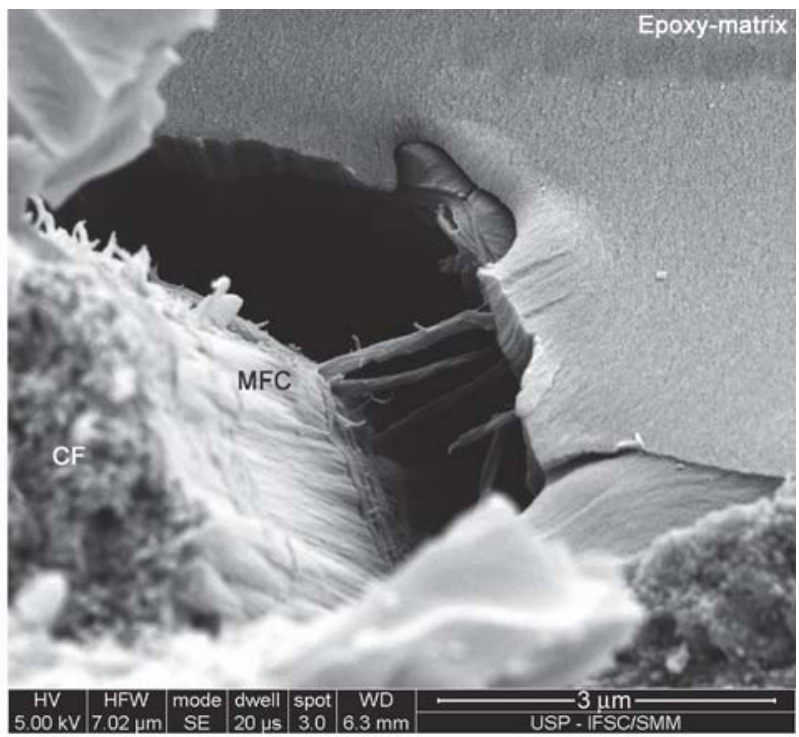

b)

Figure 9. (a) Fracture topography of tensile test coupon showing cellulose fibrils located at the interphase region: black arrows point out nanofibers with diameters of 90,50 and $180 \mathrm{~nm}$ (from the left- to the right-hand side), respectively; (b) hierarchical CFRP composite displaying MFC links between CF and epoxy resin phases after flexural fracture 
fibril-debonding, fibril-pullout and fibril-bridging. One can also infer from this image that fracture occurs at the frontier between the interphase (i.e., the MFC-enriched epoxy resin layer covering $\mathrm{CF}$ ) and the bulk resin matrix, at a distance previously estimated by the AFM technique as slightly larger than $400 \mathrm{~nm}$ from the CF surface. It is worth noting that Figures $2 \mathrm{e}$ and $2 \mathrm{f}$ gave clues that the effective MFC penetration range into the epoxy resin matrix would indeed have this order of magnitude.

Figure $9 b$ presents the flexural micro-fracture morphology of the two-level hierarchical structure based on CF and MFC constituents. Some MFC fibrils still link the $\mathrm{CF}$ and polymer matrix phases, demonstrating its effectiveness as a load transmitting and distribution media to the main $\mathrm{CF}$ reinforcing framework when stress is applied to the bulk polymer matrix. In fact, this is an effective energy relief mechanism to preserve the weakest phase, i.e., the brittle epoxy resin from fracturing. The essential nanostrengthener and nanotoughener roles of the MFC in the CFRP composite laminate are then clearly shown.

\section{Conclusions}

An innovative manufacturing method to produce highly cost-effective epoxy matrix composite laminates founded on the facile incorporation of microfibrillated cellulose directly in unsized carbon fiber performs, has been developed and presented. Having as a baseline the mechanical performance of simply unsized carbon fiber-reinforced laminate, stiffness gains of 28,20 and $86 \%$ were attained by the hierarchically conceived composite laminate under tensile, flexural and shear strength testing, respectively. U1timate strength increments of 26,49 and $77 \%$ were also attained by the novel material according those mechanical testing methodologies. The tenacity at ultimate load increased by 63,74 and $66 \%$, respectively. The general improvement in mechanical performance of the fiber-reinforced polymer laminate is credited to the $425 \mathrm{~nm}$-thick micro-fibrillated cellulose-rich interphase developed in between the carbon fiber and epoxy resin bulks, which was thoroughly characterized and measured at the nanoscale via atomic force microscopy. Strengthening and toughening mechanisms at the micro- and nanolevels have been clearly identified and portrayed by scanning electron microscopy.
This research is expected to contribute effectively to the market expansion for continuous fiber-reinforced-polymer matrix composites exhibiting excellent performance/cost ratios.

\section{Acknowledgements}

We gratefully acknowledge the scholarships provided by $\mathrm{CNPq}$ - Brazilian Council for Scientific and Technological Development to U.B.E.B. (process number 140339/2015-9), by CAPES (Coordination for the Improvement of Higher Education Personnel) to C.E.M.S., and to CNPEM (National Research Center for Energy and Materials: research proposal AFM 20681) and researcher Carlos Costa for their helpful contribution.

\section{References}

[1] Kim J-K., Mai Y-W.: High strength, high fracture toughness fibre composites with interface control - A review. Composites Science and Technology, 41, 333-378 (1991). https://doi.org/10.1016/0266-3538(91)90072-W

[2] Pegoretti A., Della Volpe C., Detassis M., Migliaresi C., Wagner H. D.: Thermomechanical behaviour of interfacial region in carbon fibre/epoxy composites. Composites Part A: Applied Science and Manufacturing, 27, 1067-1074 (1996).

https://doi.org/10.1016/1359-835X(96)00065-6

[3] Drzal L. T., Rich M. J., Lloyd P. F.: Adhesion of graphite fibers to epoxy matrices: I. The role of fiber surface treatment. The Journal of Adhesion, 16, 1-30 (1983).

https://doi.org/10.1080/00218468308074901

[4] Karger-Kocsis J., Mahmood H., Pegoretti A.: Recent advances in fiber/matrix interphase engineering for polymer composites. Progress in Materials Science, 73, 143 (2015)

https://doi.org/10.1016/j.pmatsci.2015.02.003

[5] Pegoretti A., Karger-Kocsis J.: Interphase engineering in polymer composites: Challenging the devil... Express Polymer Letters, 9, 838 (2015).

https://doi.org/10.3144/expresspolymlett.2015.78

[6] Qian H., Greenhalgh E. S., Shaffer M. S. P., Bismarck A.: Carbon nanotube-based hierarchical composites: A review. Journal of Materials Chemistry, 20, 4751-4762 (2010).

https://doi.org/10.1039/C000041H

[7] Kim H., Oh E., Hahn H. T., Lee K-H.: Enhancement of fracture toughness of hierarchical carbon fiber composites via improved adhesion between carbon nanotubes and carbon fibers. Composites Part A: Applied Science and Manufacturing, 71, 72-83 (2015).

https://doi.org/10.1016/j.compositesa.2014.12.014

[8] Giannopoulos G. I., Kallivokas I. G.: Mechanical properties of graphene based nanocomposites incorporating a hybrid interphase. Finite Elements in Analysis and Design, 90, 31-40 (2014).

https://doi.org/10.1016/j.finel.2014.06.008 
[9] Hadden C. M., Klimek-McDonald D. R., Pineda E. J., King J. A., Reichanadter A. M., Miskioglu I., Gowtham S., Odegard G. M.: Mechanical properties of graphene nanoplatelet/carbon fiber/epoxy hybrid composites: Multiscale modeling and experiments. Carbon, 95, 100-112 (2015).

https://doi.org/10.1016/j.carbon.2015.08.026

[10] Kong Q-Q., Liu Z., Gao J-G., Chen C-M., Zhang Q., Zhou G., Tao Z-C., Zhang X-H., Wang M-Z., Li F., Cai R.: Hierarchical graphene-carbon fiber composite paper as a flexible lateral heat spreader. Advanced Functional Materials, 24, 4222-4228 (2014).

https://doi.org/10.1002/adfm.201304144

[11] Tiwari S., Bijwe J., Panier S.: Strengthening of a fibrematrix interface. A novel method using nanoparticles. Nanomaterials and Nanotechnology, 3, 3/1-3/8 (2013) https://doi.org/10.5772/56213

[12] Tiwari S., Bijwe J.: Various ways to strengthen the fibermatrix interface for enhanced composite performance. Surface and Interface Analysis, 45, 1838-1848 (2013). https://doi.org/10.1002/sia.5330

[13] Ganesan Y., Peng C., Lu Y., Loya P. E., Moloney P., Barrera E., Yakobson B. I., Tour J. M., Ballarini R., Lou $\mathrm{J} .:$ Interface toughness of carbon nanotube reinforced epoxy composites. ACS Applied Materials and Interfaces, 3, 129-134 (2011). https://doi.org/10.1021/am1011047

[14] Lv P., Feng Y-Y., Zhang P., Chen H-M., Zhao N., Feng $\mathrm{W}$. Increasing the interfacial strength in carbon fiber/ epoxy composites by controlling the orientation and length of carbon nanotubes grown on the fibers. Carbon, 49, 4665-4673 (2011).

https://doi.org/10.1016/j.carbon.2011.06.064

[15] Zhang Q., Liu J., Sager R., Dai L., Baur J.: Hierarchical composites of carbon nanotubes on carbon fiber: Influence of growth condition on fiber tensile properties. Composites Science and Technology, 69, 594-601 (2009). https://doi.org/10.1016/j.compscitech.2008.12.002

[16] Asadi A., Miller M., Moon R. J., Kalaitzidou K.: Improving the interfacial and mechanical properties of short glass fiber/epoxy composites by coating the glass fibers with cellulose nanocrystals. Express Polymer Letters, 10, 587-597 (2016).

https://doi.org/10.3144/expresspolymlett.2016.54

[17] Uribe B. E. B., Carvalho A. J. F., Tarpani J. R.: Low-cost, environmentally friendly route to produce glass fiberreinforced polymer composites with microfibrillated cellulose interphase. Journal of Applied Polymer Science, 133, 44183/1-44183/9 (2016).

https://doi.org/10.1002/app.44183

[18] Siró I., Plackett D.: Microfibrillated cellulose and new nanocomposite materials: A review. Cellulose, 17, 459494 (2010).

https://doi.org/10.1007/s10570-010-9405-y
[19] Carvalho A. J. F.: Nanocelluloses from eucalyptus wood pulp. Journal of Renewable Materials, 2, 118-122 (2014).

https://doi.org/10.7569/JRM.2014.634108

[20] Siqueira G., Bras J., Dufresne A.: Luffa cylindrica as a lignocellulosic source of fiber, microfibrillated cellulose and cellulose nanocrystals. Bio-Resources, 5, 727-740 (2010).

[21] Gabr M. H., Elrahman M. A., Okubo K., Fujii T.: Effect of microfibrillated cellulose on mechanical properties of plain-woven CFRP reinforced epoxy. Composite Structures, 92, 1999-2006 (2010).

https://doi.org/10.1016/j.compstruct.2009.12.009

[22] Gabr M. H., Elrahman M. A., Okubo K., Fujii T.: Interfacial adhesion improvement of plain woven carbon fiber reinforced epoxy filled with micro-fibrillated cellulose by addition liquid rubber. Journal of Materials Science, 45, 3841-3850 (2010). https://doi.org/10.1007/s10853-010-4439-y

[23] Wang P., Drapier S., Molimard J., Vautrin A., Minni J. C.: Numerical and experimental analyses of resin infusion manufacturing processes of composite materials. Journal of Composite Materials, 46, 1617-1631 (2012). https://doi.org/10.1177/0021998311421990

[24] Poorzeinolabedin M., Parnas L., Dashatan S. H.: Resin infusion under flexible tooling process and structural design optimization of the complex composite part. Materials and Design, 64, 450-455 (2014).

https://doi.org/10.1016/j.matdes.2014.08.008

[25] Shi Y., Wang B.: Mechanical properties of carbon fiber/ cellulose composite papers modified by hot-melting fibers. Progress in Natural Science: Materials International, 24, 56-60 (2014).

https://doi.org/10.1016/j.pnsc.2014.01.006

[26] Pönni R., Vuorinen T., Kintturi E.: Proposed nano-scale coalescence of cellulose in chemical pulp fibers during technical treatments. BioResources, 7, 6077-6108 (2012).

[27] Fleck N., Jelf P., Curtis P.: Compressive failure of laminated and woven composites. Journal of Composites Technology and Research, 17, 212-220 (1995). https://doi.org/10.1520/CTR10485J

[28] Rosselli F., Santare M. H.: Comparison of the short beam shear (SBS) and interlaminar shear device (ISD) tests. Composites Part A: Applied Science and Manufacturing, 28, 587-594 (1997). https://doi.org/10.1016/S1359-835X(97)00009-2

[29] Granata R. D., Hartt W., Carlsson L., Mahfuz H., Drzal L.: Durability of composite materials and structures. Office of Naval Research, Final Technical Report, p.14 (2009).

[30] Stark W., Jaunich M., McHugh J.: Dynamic mechanical analysis (DMA) of epoxy carbon-fibre prepregs partially cured in a discontinued autoclave analogue process. Polymer Testing, 41, 140-148 (2015). https://doi.org/10.1016/j.polymertesting.2014.11.004 
[31] Goertzen W. K., Kessler M. R.: Dynamic mechanical analysis of carbon/epoxy composites for structural pipeline repair. Composites Part B: Engineering, 38, 19 (2007).

https://doi.org/10.1016/j.compositesb.2006.06.002

[32] Keusch S., Haessler R.: Influence of surface treatment of glass fibres on the dynamic mechanical properties of epoxy resin composites. Composites Part A: Applied Science and Manufacturing, 30, 997-1002 (1999). https://doi.org/10.1016/S1359-835X(99)00007-X

[33] Dong S., Gauvin R.: Application of dynamic mechanical analysis for the study of the interfacial region in carbon fiber/epoxy composite materials. Polymer Composites, 14, 414-420 (1993). https://doi.org/10.1002/pc.750140508

[34] Mohanty S., Verma S. K., Nayak S. K.: Dynamic mechanical and thermal properties of MAPE treated jute/ HDPE composites. Composites Science and Technology, 66, 538-547 (2006).

https://doi.org/10.1016/j.compscitech.2005.06.014

[35] Lu J., Askeland P., Drzal L. T.: Surface modification of microfibrillated cellulose for epoxy composite applications. Polymer, 49, 1285-1296 (2008). https://doi.org/10.1016/j.polymer.2008.01.028

[36] Li Y., Li M., Gu Y., Zhang Z., Guan P.: Investigation of the nanoscale mechanical properties of carbon fiber/ epoxy resin interphase. I. Analysis of fiber-stiffening effect during the nanoindentation process based on numerical simulation. Polymer Composites, 33, 1387 1394 (2012).

https://doi.org/10.1002/pc.22265
[37] Munz M., Sturm H., Schulz E., Hinrichsen G.: The scanning force microscope as a tool for the detection of local mechanical properties within the interphase of fibre reinforced polymers. Composites Part A: Applied Science and Manufacturing, 29, 1251-1259 (1998). https://doi.org/10.1016/S1359-835X(98)00077-3

[38] Gu Y., Li M., Wang J., Zhang Z.: Characterization of the interphase in carbon fiber/polymer composites using a nanoscale dynamic mechanical imaging technique. Carbon, 48, 3229-3235 (2010). https://doi.org/10.1016/j.carbon.2010.05.008

[39] Li M., Wang J., Zhang Z., Gu Y.: Characterization of the interphase width in carbon fibre reinforced epoxy resin composites. in 'Proceedings of the $17^{\text {th }}$ International Conference on Composite Materials. Edinburgh, United Kingdom' p8. (2009).

[40] Wu Q., Li M., Gu Y., Wang S., Zhang Z.: Imaging the interphase of carbon fiber composites using transmission electron microscopy: Preparations by focused ion beam, ion beam etching, and ultramicrotomy. Chinese Journal of Aeronautics, 28, 1529-1538 (2015). https://doi.org/10.1016/j.cja.2015.05.005

[41] Williams J. G., Donnellan M. E., James M. R., Morris W. L.: Properties of the interphase in organic matrix composites. Materials Science and Engineering, 126, 305-312 (1990).

https://doi.org/10.1016/0921-5093(90)90137-R 